\title{
Article \\ Co-Occurrence of Online and Offline Victimization: A Latent Class Analysis in University Students
}

\author{
Josep-Maria Tamarit-Sumalla ${ }^{1,2}(0)$, Claudia Malpica-Lander ${ }^{3}\left(\mathbb{D}\right.$ and Victòria Fernández-Cruz ${ }^{1, *}$ \\ 1 Faculty of Law and Social Sciences, Universitat Oberta de Catalunya, 08018 Barcelona, Spain; \\ jtamarit@uoc.edu \\ 2 Department of Public Law, Faculty of Law and Economy, University of Lleida, 25001 Lleida, Spain \\ 3 Internet Interdisciplinary Institute, Universitat Oberta de Catalunya, 08018 Barcelona, Spain; \\ cmalpica@uoc.edu \\ * Correspondence: vfernandezc@uoc.edu
}

check for updates

Citation: Tamarit-Sumalla, Josep-Maria, Claudia Malpica-Lander, and Victòria Fernández-Cruz. 2022. Co-Occurrence of Online and Offline Victimization: A Latent Class Analysis in University Students. Social Sciences 11: 16. https:// doi.org/10.3390/socsci11010016

Academic Editor: Nigel Parton

Received: 25 November 2021 Accepted: 30 December 2021

Published: 6 January 2022

Publisher's Note: MDPI stays neutral with regard to jurisdictional claims in published maps and institutional affiliations.

Copyright: (C) 2022 by the authors. Licensee MDPI, Basel, Switzerland. This article is an open access article distributed under the terms and conditions of the Creative Commons Attribution (CC BY) license (https:// creativecommons.org/licenses/by/ $4.0 /)$.

\begin{abstract}
Most people are exposed to risks both in the online and offline world. Several studies have provided definitions and measures of cybervictimization based on different theoretical approaches and most of them have focused on specific forms of cybercrime, depicting a limited portrayal of victimization. The current study explored victimization configurations in a sample of 749 university undergraduates from Spain $(61.6 \%$ women; $\mathrm{M}$ age $=26.9)$, utilizing latent class analyses to account for the nature and frequency of various types of online and offline victimization along their life span. Among them, 35.9\% were victims of a cyberattack, $24.4 \%$ reported being victims of cyberfraud and $49 \%$ of property crime. The analysis uncovered two classes of cybervictims-consisting of economic cybervictimization (victims of economic cybercrimes only) and cyber-polyvictimization (victims of various types of cybercrimes) - and allowed us to compare them with a group of non-victims. Younger respondents (15 to 25 years old), conventional university students, women, people with lower incomes and LGBTQI+ individuals have a higher representation in the cyber-polyvictimization class. In addition, members of this class have suffered more offline victimization in all the areas analyzed. The present study has found co-occurrence between online and offline victimization, thus reinforcing the relevance of simultaneously studying both areas and the interaction between them. From this empirical ground, prevention strategies should not be focused merely on opportunity factors related to the online interactions and behavior of potential victims, without facing the deep human and social roots of victimization.
\end{abstract}

Keywords: co-occurrence; latent classes; online victimization; offline victimization; victimology; polyvictims

\section{Introduction}

\subsection{Cybercrime and Cybervictimization}

In the study of cybercrime and cybervictimization, a wide repertoire of behaviors has been considered as a matter of interest by researchers. Cybercrime includes any illegal activity carried out online with the use of computers or any other devices that can connect to the internet (Kaakinen et al. 2018). Examples of behaviors defined as cybercrime are cyberbullying, cyberstalking, online theft, financial and identity theft, hate speech, child pornography, online grooming, sexual harassment, and revenge porn (DeMarco et al. 2017). The repertoire is broad and heterogeneous. To facilitate the study of these conducts, some researchers created their own classification criteria. Wall (2007) differentiated three categories: crimes against the machine ("computer integrity" crimes), crimes using machines (computer-related crimes) and crimes in the machine ("computer content" crimes). McGuire and Dowling (2013) proposed a more simplified classification, differentiating cybercrimes into cyber-enabled and cyber-dependent crimes. The first are 
those behaviors that, traditionally, have been carried out offline and that are now being displaced to the cyberspace, since the authors use the internet as a new means to perpetrate them. The second group is integrated by those conducts that would not exist without the appearance of the internet. These would be the "true" cybercrimes (or third generation), "which are solely the product of opportunities created by the internet" (Wall 2007). These classifications have been refined through recent studies that have shown how certain criminal behaviors occur simultaneously in the physical and online fields. Caneppele and Aebi (2019) propose a triple classification of crimes distinguishing between online, offline and hybrid crimes (those that occur both in the physical and virtual world).

Most empirical studies on cybervictimization have analyzed what factors, specific in cyberspace, increase the risk of suffering online victimization. Many of these studies have used samples composed of minors and have focused their attention on personal risk factors or on their vital environment, analyzing specific types of victimization (e.g., cyberbullying or sexting) (Nedelec 2018). In Spain, the studies also have delt mainly with minors and some types of victimization like peer victimization, bullying and cyberbullying or online sexual grooming (e.g., Gómez-Baya et al. 2019; Garmendia Larrañaga et al. 2019; Martínez-Ferrer et al. 2018; Villacampa and Gómez 2017). This fact is not surprising, since the use and access to the internet is much greater for minors and adolescents than for the adult population (Kaakinen et al. 2018).

The routine activity theory (Cohen and Felson 1979) has become one of the most supported theories in explaining online victimization (Miró 2012). According to this conceptual framework, the risk of victimization increases when there is a motivated offender, a suitable target and an absent or incapable guardian in time and space (e.g., Holt and Bossler 2008; Reyns et al. 2019; Reyns et al. 2011; Reyns et al. 2012). Up to now, several studies have shown that routine activities associated to online communication increase the likelihood of suffering different forms of cybervictimization. The lifestyle theory (Hindelang et al. 1978) has also been taken into consideration to explain why and how crime victimization has been transformed as a consequence of the influence of the internet on human interactions. On this basis, Aebi and Linde (2010) considered the use of the internet as a major change in the lifestyles of Western societies and linked it to the decline of traditional (offline) victimization that would be replaced by new forms of victimization in the cyberspace. Other studies have supported the thesis that engaging in deviant lifestyles online can also increase the risk of victimization (Holt and Bossler 2008). Research development has led to a convergence of the two theories into a perspective often referred to as a lifestyle-routine activity theory (Reyns et al. 2011). On this basis, in a recent study by Reyns et al. (2019), in addition to confirming that daily activities in the cyberspace are related to the risk of victimization, they concluded that the character of cybervictimization will differ according to the type of online activity that is carried out. One of the critiques or limitations presented by investigations that were based on this theory is that they do not take into account certain individual characteristics of the victim that could explain the reasons why they carry out these specific activities and that they can therefore influence the risk of (cyber) victimization (Nedelec 2018).

\subsection{Online and Offline Victimization}

Several studies have indicated that there is an overlap between online and offline victimization (Gómez-Baya et al. 2019; Kaakinen et al. 2018; Maas et al. 2019; López-Cepero et al. 2018; Marganski and Melander 2018; Nedelec 2018; Wright et al. 2019). This is a consequence of the fact that most people are exposed to risks in the offline world as well as in the cyberspace. These results challenge the perception of online and offline victimization as two separate fields and the assumption that studying cybervictimization should be based exclusively on the specific risk factors related to the activities of potential victims in the cyberspace. Therefore, the interaction between the two worlds must be taken into account when we study victimization (Nedelec 2018). 
Studies about online and offline victimization with adults are scarce. However, there are some results that will be summarized below. Mitchell et al. (2007) analyzed a sample of 929 adults with the objective of learning about the relationship between the use of the internet and its negative consequences, both in the online and offline fields. They identified a first group of adults $(n=261)$ in which it was evidenced that having experiences on the internet such as online infidelity, pornography use or internet addiction was associated with a higher risk of victimization. That is, they presented high percentages of harassment, fraud, stealing or deception victimization. The results of this research show that their interaction both with the online and the offline world had an influence on victimization.

Following this line of research, Gini et al. (2019) have recently carried out a similar study with a sample of 1377 Italian adolescents and young adults $(M=16.13)$. Through an analysis of latent classes, they were able to identify four groups of victims: peer victimization online (9.2\%), peer victimization offline $(9.2 \%)$, dual victimization (peer victimization on- and offline) (2.1\%) and those who are not victimized (79.6\%). They focused only on peer victimization (bullying and cyberbullying) based on the motives for using the internet. The dual victimization group, although not the most prevalent, presented more mismatches than the rest in online interactions, such as visiting adult sites, playing role-play games, spending more time on the internet and using online media to avoid offline interactions. According to another study, sharing images of sexual content under pressure or coercion also seems to be a predictor for the perpetration and victimization of teen dating violence (Bianchi et al. 2018). The results of some studies have not provided us with enough details on the interaction between online victimization and offline experiences, inasmuch as they have been mostly oriented to uncover risk factors focused on the online behavior of potential victims. Reyns et al. (2011), in a study on cyberstalking victimization, aimed to test the adaptation of the lifestyle-routine activity perspective to cyberspace. Although their study focused mainly on online risky behaviors, it introduced some offline risky activities usually not explored empirically by researchers, such as alcohol consumption, frequency of party attendance or bar and night club patronage, as control variables. Although these activities were not found to have an influence on online victimization, authors suggest that future research should address the possible overlap between stalking and cyberstalking.

Recent studies have analyzed the co-occurrence of online and offline victimization. In a study conducted by Marganski and Melander (2018) a sample of 540 undergraduates was analyzed. The study showed that $73 \%$ of the undergraduates $(n=394)$ reported experiencing some type of intimate partner online victimization (harassing behaviors) and, over half of them $(56 \%, n=294)$ reported having been victims of some type of in-person intimate partner violence during the year before. All respondents who reported offline intimate partner psychological, physical, or sexual victimization also reported having experienced intimate partner online victimization. Additionally, intimate partner online victimization was found to be a significant predictor of in-person partner psychological victimization. However, Reyns and Fisher (2018) found that the relationship between the online and offline domains was more nuanced. Although they found that being stalked offline increases the likelihood of being stalked online, differences in relation to gender were observed. Women who were victims of cyberstalking were less likely to be offline victims. However, this was not the same for men, who were at higher risk of being offline stalked if they were previously online victims. These results indicate that offline victimization was a predictor of online victimization in women, but not in men.

Overall, research has found that victimization experienced through ICT often overlaps with in-person victimization. However, research with an adult population is still scarce and some data are inconsistent in relation to gender, hence the need for further research.

\subsection{Polyvictimization and On- and Offline Victimization}

Beyond cybercrime, empirical research has repeatedly revealed that various types of victimization tend to co-occur. The study of co-occurrence is seen as a more consistent approach than the observation of victimization as a heterogeneous amount of isolated 
phenomena (Hamby and Grych 2013). From this approach, it has been observed that victims of violence often experience various types of violence during their lifetime. Child abuse and witnessing parental violence has been found to be the best predictor of intimate partner violence and other types of violence in adulthood (Widom et al. 2008). Revictimization studies have shown that childhood sexual abuse, physical abuse and neglect predict physical and sexual victimization into middle adulthood (McIntyre and Widom 2011). Hamby et al. (2010) have revealed that witnessing partner violence is very closely associated with several forms of exposure to other forms of family violence (OR ranging from 3.88 to 9.15). Additionally, in a study based on data from the American National Survey of Children's Exposure to Violence $(n=4549)$ they found that $34 \%$ of youth who witnessed partner violence had also been maltreated in the year before, compared with $8.6 \%$ of nonwitnesses (Hamby et al. 2010). With regard to intimate partner violence, psychological, physical and sexual violence often co-occur too (Grest et al. 2018; Sumalla et al. 2020).

In this line of research, polyvictimization has been identified as being a consistent entity to understand patterns of victimization in childhood and also in adulthood with a cumulative negative influence (Turner et al. 2010). It is, in addition, associated to most serious psychological consequences for victims (Finkelhor et al. 2007). In a study based on a community sample of people aged between 12 and 17 in Catalonia, Pereda et al. (2014) found that almost $20 \%$ of the respondents could be classified as polyvictims and $4 \%$ had experienced seven or more types of victimization. Those lifetime polyvictims had not only been affected by a high number of incidents, but they also had experienced victimization in several areas, such as conventional crimes, victimization by caregivers, peer victimization, sexual victimization and online victimization. The authors revealed that the prevalence of polyvictims was $65 \%$ in a sample of minors from the juvenile justice system (Pereda et al. 2017). Moreover, some studies have pointed out that "technology could potentially increase negative effects for polyvictims by creating additional contexts in which victimization and perpetration could occur" (Mitchell et al. 2018). Once again, studies that take into account online and offline victimization and polyvictimization are scarce. However, in recent studies it has been pointed out that becoming a victim of abuse in adolescence (domestic violence, childhood maltreatment) is correlated with carrying out risky sexual behaviors, both in the offline field (intercourse without a condom, intercourse while drunk or high) and online (visiting porn sites, cybersex, sexting, etc.) (Mitchell et al. 2018). It is also associated with a greater probability of physical violence (Maas et al. 2019; Noll et al. 2013). In the peer victimization scene, two studies have been elaborated. First, Mitchell et al. (2018) found that those adolescents $(n=791)$ who were at higher risk of peer harassment online and offline, either as a victim or a perpetrator, were those who experienced polyvictimization. Similarly, Semenza (2019) found that those adolescents who experienced polyvictimization were at higher risk of peer victimization.

In a recently published study with a large sample of adult population in the Netherlands $(n=3021)$, about $6 \%$ had experienced different types of cybervictimization, such as unauthorized access to computers, virus infection, reception or unsolicited digital messages, theft of credit card or online intimidation; and various types of in-person victimization, such as burglary, theft, damaged property or physical maltreatment (Nedelec 2018). This study also concludes that some individual differences, such as impulsivity, are associated with the likelihood of experiencing both on- and offline victimization.

\section{Objective}

The present study has been approached on the basis that cybervictimization should not be observed as a phenomenon isolated from other types of victimization. From this consideration, we hypothesized that a relevant part of victims of cybercrime have also experienced in person victimization and this co-occurrence and the existence of patterns of victimization that are not intrinsic to the cyberspace are key aspects to be taken into account when examining cybercrime and their impact on the victims. In order to validate or refute this hypothesis, we designed a study based on a survey by which we explored online 
and offline victimization experiences in a sample of university undergraduates, utilizing various analyses to account for the nature and frequency of various types of online and offline victimization along their life span. After reviewing the existing literature, we will present the methodology of our study, the main findings and, finally, a discussion and recommendations related to prevention and intervention strategies and to further research.

\section{Methods}

The data were obtained from a survey made to a sample of students from three universities in Spain, two of them conventional universities located in Catalonia and an online university. The instrument was a self-administered survey operated through the software application LimeSurvey, accessible by the students through a virtual aula. In order to make it available to the students, we contacted with academic staff from different undergraduate courses. Some of them put an announcement in their virtual aula with a link to the questionnaire. Students could open and decide, on a voluntary basis, to access and complete the survey. The survey was accessible and operating between March and April 2017 for the students of the online University, and between March and April 2018 for the students of the other two Universities. Around 10\% of the total number of students that potentially could access the survey entered and most of them completed the form regularly. The number of valid answers obtained was 749 .

\subsection{Sample}

Respondents were 467 women (61.5\%), 282 men (37.7\%) and 4 other. With regard to age, all of them were adults, the mean was 26.9 and the median 22 . Their nationality was mostly Spanish (95\%) and most of them lived in Catalonia (82\% vs. $15 \%$ living in other parts of Spain). Most of the respondents were living in a family environment at the time of the survey (52\%). In total, 27\% lived with a partner (with or without children), 11\% lived alone and only $9 \%$ with friends. In total, $43 \%$ declared that they had a partner relationship, $43 \%$ were single, $12 \%$ were married and $3 \%$ were divorced, separated or widowed. The economic background was diverse, but mostly the respondents had a middle or low class status: family incomes declared by them were between 20,000 and 40,000 euros in $43.5 \%$ of cases, less than 20,000 in $39 \%$, between 40,000 and 60,000 in $17 \%$ and more than 60,000 only in $5 \%$.

All respondents were undergraduate students, mainly majoring in social sciences, law or arts degrees (55\%). Other common majors were engineering or experimental sciences $(20 \%)$, psychology or educational sciences $(20 \%)$ and other (5\%). In total, $53 \%$ studied in a conventional university and $47 \%$ in the online university. With regard to the language chosen to complete the survey, Catalan was used in $70 \%$ of cases and Spanish in 30\%.

\subsection{Measures}

We obtained data from a set of items related to cybervictimization, with two items referred to economic cybervictimization (cyberattack and cyberfraud) and twelve items referred to social cybervictimization, two of them of sexual nature (Table 1). We also collected information related to five types of offline victimization: (1) property victimization (theft, robbery and burglary), (2) violent victimization (assaults and corporal injuries, excluding family and intimate partner violence), (3) family violence (physical and psychological), (4) intimate partner violence (physical and psychological), (5) sexual victimization, with three items: sexual aggression, sexual abuse and sexual harassment, ${ }^{1}$ and (6) child victimization, with four items: sexual aggression, sexual abuse, physical maltreatment and exposure to parents' violence. All items surveyed referred to victimization in adulthood except for those concerning child victimization, in which respondents were asked to declare facts experienced up to when they became 18 years old. 
Table 1. Prevalence of cybervictimization and offline victimization $(\%)(n=749)$.

\begin{tabular}{|c|c|c|c|}
\hline & Women & Men & Total \\
\hline \multicolumn{4}{|l|}{ Cybervictimization } \\
\hline \multicolumn{4}{|l|}{ Economic Cybervictimization } \\
\hline Cyberfraud & 25.3 & 23.0 & 24.4 \\
\hline Cyberattack & 35.5 & 36.5 & 35.9 \\
\hline \multicolumn{4}{|l|}{ Social Cybervictimization } \\
\hline Identity fraud & 9.9 & 9.9 & 9.9 \\
\hline Have been spied and/or persecuted & 7.7 & 6.4 & 7.2 \\
\hline Have been insulted and/or humiliated & 25.3 & 22.0 & 24.0 \\
\hline Have been threatened or coerced & 11.1 & 10.3 & 10.8 \\
\hline Disseminated personal information and/or not sexual images without consent & 7.5 & 9.2 & 8.1 \\
\hline Disseminated slander and/or false rumors & 10.9 & 8.5 & 10.0 \\
\hline Isolated of excluded from virtual groups & 7.9 & 5.0 & 6.8 \\
\hline Disseminated slander and/or false rumors about other persons with the intention to harm & 4.7 & 5.0 & 4.8 \\
\hline Have been obliged or forced to do or to see sexual acts & 15.8 & 11.3 & 14.2 \\
\hline Disseminated intimate images and/or explicit sexual images without consent & 2.6 & 3.9 & 3.1 \\
\hline \multicolumn{4}{|l|}{ Offline victimization } \\
\hline \multicolumn{4}{|l|}{ Property Victimization } \\
\hline Theft or robbery & 35.8 & 41.9 & 38.1 \\
\hline Burglary & 16.8 & 23.4 & 20.9 \\
\hline Violent victimization (excluded family and partner) & 14.8 & 28.4 & 19.9 \\
\hline \multicolumn{4}{|l|}{ Family Violence } \\
\hline Unidirectional physical violence & 9.4 & 8.2 & 8.9 \\
\hline Unidirectional psychological violence & 18.4 & 9.2 & 15.0 \\
\hline Bidirectional physical violence & 10.3 & 9.2 & 9.9 \\
\hline Bidirectional psychological violence & 15.8 & 10.6 & 13.9 \\
\hline \multicolumn{4}{|l|}{ Intimate partner violence } \\
\hline Unidirectional physical violence & 7.7 & 6.4 & 7.2 \\
\hline Unidirectional psychological violence & 22.1 & 12.4 & 18.4 \\
\hline Bidirectional physical violence & 6.9 & 2.5 & 5.2 \\
\hline Bidirectional psychological violence & 16.1 & 9.2 & 13.5 \\
\hline \multicolumn{4}{|l|}{ Sexual Victimization } \\
\hline Sexual aggression & 13.7 & 1.1 & 8.9 \\
\hline Sexual abuse & 16.1 & 2.5 & 10.9 \\
\hline Sexual harassment & 20.1 & 3.9 & 14.0 \\
\hline \multicolumn{4}{|l|}{ Child Victimization (under 18 years old) } \\
\hline Sexual aggression & 4.7 & 1.8 & 3.6 \\
\hline Sexual abuse & 10.7 & 3.9 & 8.1 \\
\hline Physical abuse & 7.1 & 7.4 & 7.2 \\
\hline Exposure to parental violence & 10.9 & 6.0 & 9.1 \\
\hline
\end{tabular}

The questionnaire was created ad hoc. As dependent variables, beyond the items mentioned in which the respondents were asked about the types and frequency of victimization experiences suffered, we surveyed whether the fact had been reported or not and, in some items, also about the seriousness and the consequences derived from it. As independent variables, we used data related to age, sex, socioeconomic status, nationality, place of residence, type of University and of studies conducted, family environment and sexual orientation.

\subsection{Analysis}

The data analysis was carried out in three stages: a descriptive analysis of the various forms of victimization, an analysis of latent classes and a logistic regression. The STATA program was used to carry out the analysis and logistic models, and the latent class model has been developed using the $\mathrm{R}$ software with the poLCA package (Linzer and Lewis 2011). First, we describe the results for each type of victimization, and then we examine the differences regarding sex, age, intimate relationship (with or without partner), 
sexual orientation (heterosexual vs. homo-, bi- or asexual), type of university (online vs. conventional), socioeconomic status (incomes), nationality (Spanish or foreigner), domestic environment (living alone, with a partner, parents or friends) and residence (urban vs. rural).

We used latent class analysis (LCA) as an adequate statistical method to group categorical presence and absence data into classes that are not directly observable. Latent class analyses have been used in victimological studies to uncover classes of victimization and to get a more profound knowledge about risk factors or variables such as gender, age or race (Cavanaugh et al. 2012; Berkowitz et al. 2015; Grest et al. 2018). In our study, the model was applied to the sample of all respondents who revealed any type of cybervictimization $(n=555 ; 73.7 \%)$. As the study was exploratory, and was not started from a prior hypothesis regarding the number of groups or classes in the sample, several models (with a range of 1 to 4 classes) were calculated and compared. After this, the number of latent classes was determined, using two criteria: the Akaike information criterion (AIC) and the Bayesian information criterion (BIC). Both are measures of the relative quality of a model and the best solution has been chosen by taking the smallest index, in this case the BIC reaching its minimum in the two-class model. An additional entropy index for accuracy was also calculated, with values close to 1 that mean better class homogeneity. The distribution in two classes had the lowest BIC (5463.43) (Table 2). Then, we compared the two classes obtained with the group of noncybervictims $(n=198 ; 26.3 \%)$. The LCA was made with all forms of victimization to determine the probability of each behavior per latent class, as well as the co-occurrence of victimizations within the latent classes.

Table 2. Indices of the latent classes analysis model.

\begin{tabular}{lccccc}
\hline & -2LL & AIC & BIC & Entropy & LRT \\
\hline 1 Class & 2802.90 & 5629.79 & 5681.62 & - & 1090.35 \\
2 Class & 2652.71 & 5355.43 & 5463.40 & 4.78 & 789.98 \\
3 Class & 2629.17 & 5498.46 & 5498.46 & 4.74 & 743.90 \\
4 Class & 2606.30 & 5534.86 & 5534.86 & 4.70 & 697.15 \\
\hline
\end{tabular}

Note: -2LL = negative log likelihood; AIC = Akaike Information Criteria; BIC = Bayesian Information Criteria LRT = Likelihood ratio/deviance statistic.

\section{Results}

\subsection{Prevalences and Bivariate Analyses}

\subsubsection{Cybervictimization}

The prevalence rate of cybervictimization (any of the 12 types surveyed) was 73.7\% (74.1\% men and $73.4 \%$ women). The most prevalent type was cyberattack $(35.9 \% ; 36.5 \%$ men, $35.5 \%$ women), then cyberfraud ( $24.4 \% ; 25.3 \%$ women, $23 \%$ men), both considered as types of economic cybervictimization. There were no significant differences regarding the different independent variables, except family environment in cyberattack, with a higher risk for those living with a partner $(44.8 \%)$, compared to other categories $\left(X^{2}=14.797\right.$; $p=0.002)$. Most of the victims of cyberattack experienced it only once $(60.5 \%)$ and they suffered damages to their computer system (67.4\%). They did not report the fact in $95 \%$ of cases. Victims of cyberfraud experienced it only once in around $80 \%$ of cases and the most part of them did not report (80\%).

Forty-one percent of respondents had experienced some type of social cybervictimization (43.4\% men, $40.9 \%$ women). We found no significant differences with regard to the independent variables, except age, being the younger respondents (between 18 and 25 years) the most victimized $\left(46.2 \% ; X^{2}=12.802 ; p=0.005\right)$. Most victims suffered any of these experiences more than twice $(56 \%)$ and the abuser was the partner or ex-partner in almost $75 \%$ of cases. Most part of them (90\%) did not report the facts.

Among various types of social cybervictimization, the most prevalent was having been insulted or humiliated (24\%). Moreover, $10.8 \%$ of respondents had been coerced, threatened or blackmailed, $10 \%$ had been slandered or defamed, $9.9 \%$ had suffered identity 
theft, $8.1 \%$ had had offensive personal information or nonsexual images disseminated, $6.8 \%$ had been excluded from virtual groups and $4.8 \%$ had suffered from slandering or defaming other persons with intention to harm them. Regarding sexual related behaviors, $14.2 \%$ of respondents had been forced to do or to see sexual actions and $3.1 \%$ had suffered from dissemination of personal explicit sexual images without their consent. There were no significant differences between men and women in any of the previous mentioned types of cybervictimization and there were no significant differences related to sociodemographic circumstances and other independent variables.

\subsubsection{Offline Victimization}

Around half of respondents (49\%; 50.4\% men, 48\% women) experienced some type of property crime (theft, robbery, or burglary). Victimization was more prevalent among those living in urban areas $(51.4 \%)$, compared to rural areas $\left(42.6 \% ; X^{2}=4.435 ; p=0.35\right)$, and among online students (53.4\%), compared to those from conventional universities $(46.1 \%$; $\left.X^{2}=5.152 ; p=0.23\right)$.

Violent victimization, consisting of assault or corporal injuries-excluding family and intimate partner violence-was experienced by nearly $20 \%$ of respondents with significant differences regarding sex $\left(28.4 \%\right.$ men and $14.8 \%$ women; $\left.X^{2}=20.388 ; p=0.00\right)$, but no differences related to other independent variables.

The prevalence rate of family violence (meaning having experienced any of the four surveyed types as a victim) was $27 \%$ (29.8\% among women and $22.3 \%$ among men; $X^{2}=4.22$; $p=0.27)$. With regard to physical violence, unidirectional victimization was experienced by $9 \%$ of respondents and bidirectional by $10 \%$, with no significant differences regarding sex. Psychological violence was more prevalent, mainly in women. Among them, 18\% experienced unidirectional victimization, being this only $9 \%$ among men. Bidirectional psychological violence was experienced by $15.8 \%$ of women and $10.6 \%$ of men.

With regard to intimate partner violence, a general prevalence rate of $22.6 \%$ was found. There is a significant difference between victimization among women (26.8\%) and men $(16 \%)\left(X^{2}=11.296 ; p=0.001\right)$. However, significant differences related to sex were not found in all types of victimization. In bidirectional physical violence, women were significantly more victimized than men $(6.9 \%$ vs. $2.5 \%$; OR $=2.158)$, but the same did not apply when violence was unidirectional. As regards psychological violence, women were significantly more victimized, both in cases of unidirectional aggression (22\% women vs. $12.4 \%$ men; $\mathrm{OR}=1.594)$ and in cases of bidirectional violence ( $16 \%$ women vs. $9.2 \%$ men; $\mathrm{OR}=1.535)$. There were also significant differences regarding types of universities, with a higher victimization rate among students in conventional universities compared to online students $\left(X^{2}=31386 ; p=0.00\right)$ and types of studies, being more at risk those studying Psychology and Education than the rest of the students surveyed $\left(X^{2}=13.01 ; p=0.01\right)$.

The prevalence of sexual victimization turned out to be $25.4 \%$, with significant differences between women $(36.6 \%)$ and men $(6.7 \%)\left(X^{2}=82.912 ; p=0.00\right)$. The percentage of people victimized throughout adulthood was $8.9 \%$ in cases of sexual assault, $10.9 \%$ in sexual abuse and $14 \%$ in sexual harassment, the differences between men and women were significant in all three items. Students from conventional universities were more victimized than those studying online $(30.3 \%$ vs. $20.9 \%)\left(X^{2}=8.817 ; p=0.03\right)$. Respondents identifying as homosexual, bisexual or asexual reported higher victimization than heterosexuals (35.8\% vs. $28 \%)\left(X^{2}=23.003 ; p=0.00\right)$. There were no significant differences with regard to the rest of the variables.

With regard to child offline victimization (meaning having experienced any of the four types as a victim), the prevalence rate was $22 \%$. Twenty-four percent of women and $20.7 \%$ of men answered that they had suffered at least one victimization experience in childhood. Differences regarding sex were significant $\left(X^{2}=9.273 ; p=0.02\right)$. Concerning types of victimization, $3.6 \%$ had been victims of sexual aggression (4.7\% among women) and $7.2 \%$ of sexual abuse (with no sex differences). Regarding physical violence (excluding corporal punishment), the prevalence rate was $7.2 \%$, and exposition to partner violence (EPV) was 
experienced by $9.1 \%$ of respondents (10.9\% among women). Regarding personal status and lifestyle circumstances, a significant difference was found between those living with a partner (rating a higher prevalence, 25.2\%) and those in any other domestic environment $(15.2 \%)\left(X^{2}=11.193 ; p=0.01\right)$ and between heterosexuals and respondents of other sexual orientations, having experienced the latter higher child victimization $\left(X^{2}=37.055 ; p=0.00\right)$.

\subsection{Latent Classes}

As we have mentioned previously, the model with two classes is theoretically more grounded than the models with three and four classes. In addition, we got the advantage of comparing every class with the group of respondents who were not affected by any type of cybercrime (26.3\%). The class membership of the 552 cybervictims (those who experienced some type of cybervictimization throughout their life, 73.7\%) reflects the probability for each subject to become only victims of economic cybercrime or to become victims of various types of cybercrime according to a pattern of polyvictimization. Members of class 1 (only economic cybervictimization, $n=425$ ) and class 2 (cyber-polyvictimization, $n=127$ ) had experienced similarly high levels of economic cybervictimization (both cyberfraud and cyberattacks), but they reveal differences regarding the prevalence of all 10 types of social cybervictimization (Table 2).

We analyzed the association between class membership and the sociodemographic measures and other independent variables. We found some significant differences in a bivariate analysis. Younger respondents (18-25 years old) are more represented in class 2 (polyvictimization) whereas older respondents (above 35 years) have higher probabilities to be members of class 1 . The difference is statistically significant $\left(X^{2}=16.706, p<0.01\right)$. Similarly, students in conventional universities are more at risk to become members of class 2 and students in the online university are more represented in class $1\left(X^{2}=9.099, p<0.01\right)$. No significant differences were found between classes 1 and 2 and between every class and the group of non cybervictims with regard to the other variables. Women, members of the LGBTQI+ community, students without partners and with lower incomes are more present in class 2 than in class 1 and among noncybervictims, but the differences are not statistically significant. A logistic regression analysis of the class 2 confirmed that the differences between age groups were significant (being lower the class membership of students over 35 years old). Moreover, significant differences were found regarding economic status, being those with lower incomes more at risk to be members of the cyber-polyvictimization class $(\mathrm{OR}=1.988)$, and sexual orientation, with homosexuals, bisexuals, and asexuals having a higher probability to be classified as polyvictims $(\mathrm{OR}=3.232)$ (Table 3$)$.

The next step was analyzing the prevalence of conventional (offline) victimization comparing members of classes 1 and 2 between them and with the group of noncybervictims. In addition to showing a pattern of cyber-polyvictimization, members of class 2 suffered higher victimization in all areas. Almost two out of three $(65.6 \%)$ were victims of property crimes, $38.3 \%$ suffered family violence, $37.5 \%$ violent non-domestic victimization, $37.5 \%$ intimate partner violence and $34.5 \%$ sexual victimization. The victimization rates were lower among the members of class 1 (economic cybervictims) and even lower among the group of noncybervictims. All these differences were statistically significant in the bivariate analysis, with $X^{2}$ ranging from 12.782 (sexual victimization; $p=0.00$ ) to 78.218 (violent non-domestic victimization; $p=0.00$ ) (Table 4). There were also differences with regard to child victimization, although they were smaller: $25 \%$ of cyber-polyvictims experienced some type of child victimization, compared to $22 \%$ of economic cybervictims and $14 \%$ of noncybervictims $\left(X^{2}=7.278 ; p<0.05\right)$ (Table 4$)$. 
Table 3. Latent classes. Differences of independent variables.

\begin{tabular}{|c|c|c|c|c|c|c|c|}
\hline & & $\begin{array}{c}\text { No } \\
\text { Cybervictims } \\
(n=197)\end{array}$ & $\begin{array}{l}\text { Economic } \\
\text { Cybervictims } \\
\quad(n=425)\end{array}$ & $\begin{array}{c}\text { Cyber- } \\
\text { Polyvictims } \\
(n=127)\end{array}$ & Total & $X^{2}$ & \\
\hline \multirow[t]{4}{*}{ Age } & $18-25$ & $63.6 \%$ & $58.1 \%$ & $75.8 \%$ & $62.5 \%$ & 16.706 & $* * *$ \\
\hline & $26-35$ & $17.7 \%$ & $21.3 \%$ & $17.2 \%$ & $19.7 \%$ & & \\
\hline & $36-45$ & $10.6 \%$ & $11.5 \%$ & $3.9 \%$ & $10 \%$ & & \\
\hline & $>45$ & $8.1 \%$ & $9.1 \%$ & $3.1 \%$ & $7.8 \%$ & & \\
\hline \multirow[t]{2}{*}{ University } & Online & $46.5 \%$ & $51.1 \%$ & $35.9 \%$ & $47.3 \%$ & 9.099 & $* * *$ \\
\hline & Conventional & $53.5 \%$ & $48.9 \%$ & $64.1 \%$ & $52.7 \%$ & & \\
\hline \multirow[t]{4}{*}{ Degree } & $\begin{array}{l}\text { Arts, Law or } \\
\text { social sciences }\end{array}$ & $60.1 \%$ & $60.4 \%$ & $57 \%$ & $59.8 \%$ & 0.976 & \\
\hline & $\begin{array}{l}\text { Engineering or } \\
\text { natural sciences }\end{array}$ & $21.2 \%$ & $19.7 \%$ & $20.3 \%$ & $20.2 \%$ & & \\
\hline & Psychology, & & & & & & \\
\hline & $\begin{array}{c}\text { Education and } \\
\text { others }\end{array}$ & $18.7 \%$ & $19.9 \%$ & $22.7 \%$ & $20.1 \%$ & & \\
\hline \multirow[t]{2}{*}{ Sex } & Woman & $62.9 \%$ & $60.7 \%$ & $66.9 \%$ & $62.3 \%$ & 1.653 & \\
\hline & Man & $37.1 \%$ & $39.3 \%$ & $33.1 \%$ & $37.7 \%$ & & \\
\hline \multirow[t]{2}{*}{ Nationality } & Spanish & $95.4 \%$ & $94.4 \%$ & $95.3 \%$ & $94.8 \%$ & 0.369 & \\
\hline & Foreigner & $4.6 \%$ & $5.6 \%$ & $4 \%$ & $5.2 \%$ & & \\
\hline \multirow[t]{2}{*}{ Residence } & Catalonia & $82.6 \%$ & $81.5 \%$ & $83.6 \%$ & $82.1 \%$ & 0.328 & \\
\hline & Other & $17.4 \%$ & $18.5 \%$ & $16.4 \%$ & $17.9 \%$ & & \\
\hline \multirow[t]{2}{*}{ Environment } & City & $73.3 \%$ & $75.9 \%$ & $74.2 \%$ & $74.9 \%$ & 0.504 & \\
\hline & Village & $26.7 \%$ & $24.1 \%$ & $25.8 \%$ & $25.1 \%$ & & \\
\hline \multirow{2}{*}{$\begin{array}{l}\text { Intimate } \\
\text { relationship }\end{array}$} & With a partner & $50.3 \%$ & $58.5 \%$ & $47.7 \%$ & $54.5 \%$ & 6.656 & \\
\hline & $\begin{array}{l}\text { Without a } \\
\text { partner }\end{array}$ & $49.7 \%$ & $41.5 \%$ & $52.3 \%$ & $45.5 \%$ & & \\
\hline \multirow[t]{3}{*}{ Incomes } & $<20,000 €$ & $30.1 \%$ & $34.4 \%$ & $42.2 \%$ & $34.6 \%$ & 7.842 & * \\
\hline & $20,000-40,000 €$ & $47.7 \%$ & $41.9 \%$ & $43 \%$ & $43.6 \%$ & & \\
\hline & $>40,000 €$ & $22.3 \%$ & $23.7 \%$ & $14.8 \%$ & $21.8 \%$ & & \\
\hline \multirow[t]{3}{*}{$\begin{array}{c}\text { Sexual } \\
\text { orientation }\end{array}$} & Heterosexual & $70.2 \%$ & $75.9 \%$ & $65.6 \%$ & $72.6 \%$ & 10.656 & * \\
\hline & $\begin{array}{c}\text { Homosexual, } \\
\text { bisexual, asexual }\end{array}$ & $6.6 \%$ & $8.7 \%$ & $13.3 \%$ & $8.9 \%$ & & \\
\hline & No answer & $23.2 \%$ & $15.5 \%$ & $21.1 \%$ & $18.5 \%$ & & \\
\hline
\end{tabular}

$* * * p<0.01, * p<0.1$.

Table 4. Latent classes. Differences related to offline victimization.

\begin{tabular}{|c|c|c|c|c|c|c|}
\hline & $\begin{array}{c}\text { Non } \\
\text { Cybervictims }\end{array}$ & $\begin{array}{c}\text { Economic } \\
\text { Cybervictims }\end{array}$ & Polycybervictims & Total & \multicolumn{2}{|c|}{ Chi-Square } \\
\hline Property crimes & $42.4 \%$ & $47.1 \%$ & $65.6 \%$ & $49 \%$ & 18.218 & $* * *$ \\
\hline Family violence & $18.7 \%$ & $27.6 \%$ & $38.3 \%$ & $27.1 \%$ & 15.259 & $* * *$ \\
\hline $\begin{array}{l}\text { Violent Victimization } \\
\text { (non-domestic) }\end{array}$ & & $23.9 \%$ & $37.5 \%$ & $19.9 \%$ & 78.265 & $* * *$ \\
\hline Intimate partner violence & $7.6 \%$ & $25.3 \%$ & $37.5 \%$ & $22.7 \%$ & 43.413 & $* * *$ \\
\hline Sexual victimization & $17.2 \%$ & $26.5 \%$ & $34.4 \%$ & $25.4 \%$ & 12.782 & $* * *$ \\
\hline Child victimization & $14.1 \%$ & $22.2 \%$ & $25 \%$ & $20.6 \%$ & 7.278 & $* *$ \\
\hline
\end{tabular}

${ }^{* * *} p<0.01,{ }^{* *} p<0.05$.

The logistic regression model for class 2 confirmed the significant differences regarding property crimes victimization $(\mathrm{OR}=3.748)$, family violence $(\mathrm{OR}=2.040)$ and intimate partner relationship $(\mathrm{OR}=11237)$ (Table 5). 
Table 5. Logistic regression for class 2 (cyber-polyvictimization) $(n=127)$.

\begin{tabular}{ccc}
\hline & $\begin{array}{c}\text { Model (Without Other Forms of } \\
\text { Victimization as a Predictor) }\end{array}$ & $\begin{array}{c}\text { Model (With Other Forms of } \\
\text { Victimization as a Predictor) }\end{array}$ \\
\hline Women & 1.047 & 0.674 \\
$26-35$ & 0.919 & 1.120 \\
$36-45$ & 0.370 & $0.242^{* *}$ \\
Older than 45 & 0.457 & $0.226^{* *}$ \\
Online University & 0.682 & 0.475 \\
Foreigner & 0.886 & 0.868 \\
Village & 0.783 & 0.926 \\
With a partner & 1.067 & 1.187 \\
Less than 20,000 & 1.510 & $1.988^{* *}$ \\
More than 40,000 & 0.795 & 1.199 \\
Not from Catalonia & 1.322 & 2.035 \\
Homosexual, bisexual, asexual & $2.265 *$ & $3.232^{* * *}$ \\
Did not respond (sexual orientation) & 0.886 & 1.454 \\
Property crimes & & $3.748^{* * *}$ \\
Family violence & & $2.040^{* *}$ \\
Intimate partner violence & & $11.237^{* * *}$ \\
Sexual victimization & & 1.682 \\
Child victimization & & 0.763 \\
Constant & 0.723 & 0.161 \\
Pseudo R2 & 0.0467 & 326 \\
\hline Observations $(n)$ & & 0.2410 \\
\hline
\end{tabular}

${ }^{* * *} p<0.01,{ }^{* *} p<0.05,{ }^{*} p<0.1$.

\section{Discussion and Conclusions}

A first observation of the results of the present study provides us only with a few parameters useful to examine the relationship between cybervictimization and other different types of victimization. Some risk factors that appear to be relevant in some forms of in-person victimization, such as sex in sexual crimes or in some forms of family and intimate partner violence, or sexual orientation, cannot be perceived in cybervictimization, in which the risk of becoming a victim seems to be more equally distributed among the population. However, the present study corroborates the relevance of the analysis of latent classes as an ideal means of examining cybervictimization and the co-occurrence of different types of online and offline victimization. While the mere observation of responses to the various types of cybervictimization does not provide results that would allow us to discern to what extent individual differences and the various sociodemographic variables influence the likelihood of someone becoming a victim, the search for latent classes has led us to visualize the existence of various hidden patterns of victimization in which aspects like age, sexual orientation or economic status appear to be relevant factors that determine an increased risk of victimization.

In addition, the analysis has led us to confirm the importance of polyvictimization as a meaningful victimological concept and the need to examine the relationship between online and offline victimization (Finkelhor et al. 2007; Reyns 2013; Pereda et al. 2014, 2017; Bianchi et al. 2018; Marganski and Melander 2018). The results that can be seen in Table 4 are in this regard very remarkable, offering us a sharp image of a cyber-polyvictimization pattern associated with high online and offline victimization. These findings have thus confirmed that cybervictimization studies that are focused only on risk exposure factors based on opportunities related to routine activities of potential victims on the internet do not provide a sufficient explanation of the complex phenomenon of cybervictimization. It is of particular interest to note that if the risk of being a victim of cyberfraud or cyberattacks is somewhat evenly spread among the population studied, the risk of suffering forms of social cybervictimization and, in particular, of being affected by various types of cybercrime, is 
largely concentrated in a part of the population also affected by forms of victimization occurred outside the cyberspace.

Beyond these issues, the study has confirmed the high prevalence of cybervictimization, especially those forms with an economic dimension (cyberfraud and cyberattacks). This finding may be related to the fact that it is a type of crime that tends to be reported more and can be easier to recognize and disclose through a survey, compared to other forms of victimization. The result that economic cybervictimization affects mostly older people and those studying at online universities (both groups largely overlap) cannot lead to conclusions, since what has been examined is victimization throughout their life. However, it should be noted that the youngest and those who study in face-to-face universities are more represented in the class of polyvictims, with significant differences even in the multivariate analysis. This could be explained, in part, by the increased exposure to risk by the younger population, which, according to various studies, has a higher level of activity on the internet (Kaakinen et al. 2018). That makes it a risky group, especially with regard to social cybervictimization, both sexual and non-sexual. However, this element alone does not explain why they also suffer from greater offline victimization, so we should also take into consideration aspects related to the lifestyle or the characteristics of students in online universities, in which we hypothetically could find some risk elements or specific factors of protection against victimization in general, which have not been discovered empirically so far and which future studies could investigate.

The study has shown, in line with other studies on victimization, the relevance of low socioeconomic status and minority (non-heterosexual) sexual orientations as risk factors for polyvictimization (Finkelhor et al. 2005; Sterzing et al. 2019). Less expected were the results revealing an association between living with a partner, being a victim of intimate partner violence (uni or bidirectional) and suffering from economic cybervictimization. Although the data analysis does not allow us to provide empirically founded explanations, this finding suggests the need to overcome a vision of economic cybervictimization focused on attacks by strangers and pay greater attention to fraud or cyberattacks that could occur in situations of intimate partner conflicts.

The above findings have theoretical and practical transcendence. First and foremost, they stress the need of studying different forms of victimization in order to confirm the linkage between online and offline victimization and the relevance of polyvictimization to understand and address the problems and needs of an important part of the population. They also reveal that the prevention of cybervictimization necessarily involves addressing the prevention of victimization in the physical world in a serious manner, especially in the field of interpersonal relationships. Moreover, taking into account the psychological impact that various forms of social cybervictimization can produce on victims, researchers and practitioners should bear in mind that those experiences in the cyberspace are largely associated with a pattern of polyvictimization in which the different types of violence in the physical world should be considered.

The results are thus reinforcing the relevance of simultaneously studying online and offline victimization and the interaction between them. The discovery of a pattern of victimization both online and offline in some victims, the substantial differences between the two areas of cybervictimization, economic and social, and the fact that the latter may have more elements in common with interpersonal victimization in the physical space, are findings that contribute arguments to the thesis that questions the concept of cybercrime as a theoretically consistent entity and sees in it, at most, a liquid reality (Bauman 2000). The results would thus validate the idea, highlighted by Wall (2008), that cybercrime is a concept constructed by the media, strengthened by social panic and not supported enough by empirical research as a consistent theoretical entity. Excluding "pure" or "true" cybercrimes, opportunities related to how individuals behave through the internet, as far as cybervictimization is concerned, can only explain a part of victimization and not its deep roots and consequences. 
These findings lead us to conclude that research on cybercrime should not be focused only on risks derived from routine activities associated to online communication, particularly sexual and other forms of social cybervictimization. Rather than assuming the idea of a disinhibition effect or other circumstances modifying the way of people behaving in the cyberspace as key factors in explaining and preventing cybercrime, researchers and practitioners should examine victimization as a complete and complex reality.

Although these suggestions can be useful to approach further research, some important limitations of the study must be recognized. A first limitation is the self-selection bias, which is common to all web-based surveys with a low response rate. A second limitation has been that the questionnaire was not adapted to a standardized instrument. This was a conscious decision, as the objective was to collect an amount of information related to various forms of victimization. Though it was at the price of operating with items in which terms such as "violence" were used, thus involving a risk of subjectivism, indetermination and depress reporting. Finally, representativity was evenly altered as a consequence of the dissonance in sex distribution (most respondents being female) and age, with a less homogenous sample than other surveys aimed at university students.

Author Contributions: Conceptualization, J.-M.T.-S.; methodology, C.M.-L.; validation, J.-M.T.-S., C.M.-L. and V.F.-C.; investigation, J.-M.T.-S., C.M.-L. and V.F.-C.; resources, J.-M.T.-S. and V.F.-C.; data curation, C.M.-L.; writing - original draft preparation, J.-M.T.-S. and V.F.-C.; writing-review and editing, V.F.-C. All authors have read and agreed to the published version of the manuscript.

Funding: This research received no external funding.

Informed Consent Statement: Informed consent was obtained from all subjects involved in the study.

Conflicts of Interest: The authors declare no conflict of interest.

\section{Note}

1 The difference between sexual aggression and sexual abuse is established by the Spanish Penal Code (SPC), which describes them as follows: sexual aggression is any sexual act-involving penetration or not-committed through violence or intimidation. It is interpreted as use of physical violence or threat to use it (art. 178 and 179 SPC). Sexual abuse is legally defined as any sexual act with a person - be it an adult or a child — executed without their consent or by abusing authority or unconsciousness and incapacity of the victim (art. $180 \mathrm{SPC}$ ).

\section{References}

Aebi, Marcelo F., and Antonia Linde. 2010. Is there a crime drop in Western Europe? European Journal on Criminal Policy and Research 16: 251-77. [CrossRef]

Bauman, Zygmunt. 2000. Liquid Modernity. Cambridge: Polity Press.

Berkowitz, Ruth, Kris Tunac De Pedro, and Tamika D. Gilreath. 2015. A latent class analysis of victimization among middle and high school students in California. Journal of School Violence 14: 316-33. [CrossRef]

Bianchi, Dora, Mara Morelli, Maria R. Nappa, Roberto Baiocco, and Antonio Chirumbolo. 2018. A bad romance: Sexting motivations and teen dating violence. Journal of Interpersonal Violence 36: 6029-6049. [CrossRef]

Caneppele, Stefano, and Marcelo F. Aebi. 2019. Crime drop or police recording flop? On the relationship between the decrease of offline crime and the increase of online and hybrid crimes. Policing: A Journal of Policy and Practice 13: 66-79. [CrossRef]

Cavanaugh, Courtenay E., Jill. T. Messing, Hanno Petras, Barbara Fowler, Lareina La Flair, Joan Kub, Jacqueline Agnew, Sheila Fitzgerald, Richelle Bloyard, and Jacquelyn C. Campbell. 2012. Patterns of violence against women: A latent class analysis. Psychol Trauma 4: 169-76. [CrossRef] [PubMed]

Cohen, Lawrence E., and Marcus Felson. 1979. Social change and criminal rate trends: A routine activity approach. American Sociological Review 44: 588-608. [CrossRef]

DeMarco, Jeffrey Nicholas, Carly Cheevers, Julia Davidson, Stefan Bogaerts, Ugo Pace, Mary Aiken, Vincenzo Caretti, Adriano Schimmenti, and Antonia Bifulco. 2017. Digital dangers and cyber-victimisation: A study of European adolescents online risky behaviors for sexual exploitation. Clinical Neuropsychiatry 14: 104-12.

Finkelhor, David, Richard K. Ormord, Heather A. Turner, and Sherry. L. Hamby. 2005. Measuring poly-victimization using the Juvenile Vivtimization Questionnaire. Child Abuse \& Neglect 29: 1297-312. [CrossRef]

Finkelhor, David, Richard K. Ormord, and Heather. A. Turner. 2007. Poly-victimization: A neglected component in child victimization. Child Abuse \& Neglect 31: 7-26. [CrossRef] 
Garmendia Larrañaga, Maialen, Estefanía Jiménez Iglesias, and Nekane Larrañaga Aizpurua. 2019. Bullying and cyberbullying: Victimisation, harassment, and harm. The need to intervene in the educational center. Revista Española de Pedagogía 77: 295-312. [CrossRef]

Gini, Gianluca, Claudia Marino, Jia-Yan Xie, Jan Pfetsch, and Tiziana Pozzoli. 2019. Associations of traditional and peer cybervictimization with adolescents' internet use: A latent profile analysis. Cyberpsychology: Journal of Psychosocial Research on Cyberspace 13: 1. [CrossRef]

Gómez-Baya, Diego, Antonia Rubio-González, and Margarida Gaspar de Maros. 2019. Online communication, peer relationships and school victimization: A one-year study during middle adolescents. International Journal of Adolescents and Youth 24: 199-211. [CrossRef]

Grest, Carolina Villamil, Jungeun Olivia Lee, Tamika Gilreath, and Jennifer Unger. 2018. Latent class analysis of intimate partner violence perpetration and victimization among Latino emergint adults. Journal of Youth and Adolescence 47: 575-85. [CrossRef]

Hamby, Sherry, and John Grych. 2013. The Web of Violence: Exploring Connections among Different Forms of Interpersonal Violence and Abuse. Springer: New York.

Hamby, Sherry, David Finkelhor, Heather Turner, and Richard Ormord. 2010. The overlap of witnessing partner violence with child maltreatment and other victimizations in a nationally representative survey of youth. Child Abuse \& Neglect 34: 734-41. [CrossRef]

Hindelang, Michael J., Michael R. Gottfredson, and James Garofalo. 1978. Victims of Personal Crime: An Empirical Foundation for a Theory of Personal Victimizarion. Cambridge: Ballinger.

Holt, Thomas J., and Adam M. Bossler. 2008. Examining the applicability of lifestyle-routine activities theory for cybercrime victimization. Deviant Behavior 30: 1-25. [CrossRef]

Kaakinen, Markus, Teo Keipi, Pekka Räsänen, and Atte Oksanen. 2018. Cybercrime victimization and subjective well-being: An examination of the buffering effect hypothesis among adolescents and young adults. Cyberpsychology, Behavior and Social Networking 21: 129-37. [CrossRef]

Linzer, Drew A., and Jeffry B. Lewis. 2011. poLCA: An R package for polytomous variable latent class analysis. Journal of Statistical Software 42: 1-29. [CrossRef]

López-Cepero, Javier, José Vallejos-Saldarriga, and María Merino-García. 2018. Digital intimate partner violence among Peruvian youths: Validation of an instrument and a theoretical proposal. Journal of Interpersonal Violence 36: 5167-5185. [CrossRef]

Maas, Megan K., Bethany C. Bray, and Jennie G. Noll. 2019. Online sexual experiences predict subsequent sexual health and victimization outcomes among female adolescents: A latent class analysis. Journal of Youth Adolescence 48: 837-49. [CrossRef]

Marganski, Alison, and Lisa Melander. 2018. Intimate partner violence victimization in the cyber and real world: Examining the extent of cyber aggression experiences and its association with in-person dating violence. Journal of Interpersonal Violence 33: 1071-95. [CrossRef]

Martínez-Ferrer, Belén, David Moreno, and Gonzalo Musitu. 2018. Are adolescents engaged in the problematic use of social networking sites more involved in peer aggression and victimization? Frontiers in Psychology 29: 801. [CrossRef]

McGuire, Mike, and Samantha Dowling. 2013. Cyber Crime: A Review of the Evidence. Summary of Key Findings and Implications. Research report 75. London: Home Office.

McIntyre, Jared Kean, and Cathy Spatz Widom. 2011. Childhood victimization and crime victimization. Journal of Interpersonal Violence 26: 640-63. [CrossRef]

Miró, Fernando. 2012. El Cibercrimen. Fenomenología y Criminología de la Delincuencia en el Ciberespacio. Madrid: Marcial Pons.

Mitchell, Kimberly J., Anna Segura, Lisa M. Jones, and Heather A. Turner. 2018. Poly-victimization and peer harassment involvement in a technological world. Journal of Interpersonal Violence 33: 762-88. [CrossRef] [PubMed]

Mitchell, Kimberly J., David Finkelhor, and Kathryn A. Becker-Blease. 2007. Classification of adults with problematic Internet experiences: Linking internet and conventional problems from a clinical perspective. CyberPsychology E Behavior 10: 381-92. [CrossRef]

Nedelec, Joseph L. 2018. Individual differences and co-occurring victimization online and offline: The role of impulsivity. Personality and Individual Differences 133: 77-84. [CrossRef]

Noll, Jennie G., Chad E. Shenk, Jaclyn. E. Barnes, and Katherine J. Haralson. 2013. Association of maltreatment with high-risk internet behaviors and offline encounters. Pediatrics 131: 510-17. [CrossRef]

Pereda, Noemí, Georgina Guilera, and Judit Abad. 2014. Victimization and poly-victimization of Spanish children and youth: Results from a community sample. Childe Abuse \& Neglect 38: 640-49. [CrossRef]

Pereda, Noemí, Judit Abad, and Georgina Guilera. 2017. Victimization and polyvictimization of Spanish youth involved in Juvenile Justice. Journal of Interpersonal Violence 32: 3272-300. [CrossRef]

Reyns, Bradford W. 2013. Online routines and identity theft victimization: Further expanding routine activity theory beyond direct-contact offenses. Journal of Research in Crime and Delinquency 50: 216-38. [CrossRef]

Reyns, Bradford W., and Bonnie S. Fisher. 2018. The relationship between offline and online stalking victimization: A gender-specific analysis. Violence and Victims 33: 769-86. [CrossRef]

Reyns, Bradford W., Billy Henson, and Bonnie S. Fisher. 2011. Being pursued online: Applying cyberlifestyle-routine activities theory to cyberstalking victimization. Criminal Justice and Behavior 38: 1149-69. [CrossRef]

Reyns, Bradford W., Billy Henson, and Bonnie S. Fisher. 2012. Stalking in the twilight zone: Extent of cyberstalking victimization and offending among college students. Deviant Behavior 33: 1-25. [CrossRef] 
Reyns, Bradford W., Bonnie S. Fisher, Adam M. Bossler, and Thomas J. Holt. 2019. Opportunity and and self-control: Do they predict multiple forms of online victimization? American Journal of Criminal Justice 44: 63-82. [CrossRef]

Semenza, Daniel C. 2019. Cross-modal peer polyvictimization and teen dating violence. Devint Behavior, 1-16.

Sterzing, Paul, Rachel Gartner, Jeremy Goldbach, Briana McGeough, Allen G. Ratliff, and Kelly C. Johnson. 2019. Polyvictimization prevalence rates for sexual and gender minority adolescents: Breaking down the silos of victimization research. Psychology of Violence 9: 419-30. [CrossRef]

Sumalla, Josep M. Tamarit, Claudia Malpica Lander, and Irene Montiel Juan. 2020. Relación entre la violencia en la pareja y otras formas de victimización: un estudio de clases latentes en población universitaria. InDret n. 2: 373-93. [CrossRef]

Turner, Heather A., David Finkelhor, and Richard Ormord. 2010. Poly-victimization in a national sample of children and youth. American Journal of Preventive Medicine 38: 323-30. [CrossRef]

Villacampa, Carolina, and María Jesús Gómez. 2017. Online child sexual grooming: Empirical findings on victimisation and perspectives on legal requirements. International Review of Victimology 23: 105-21. [CrossRef]

Wall, David S. 2007. Policing cybercrimes: Situating the public police in networks of security within cyberspace. Police Practice and Research: An International Journal 8: 183-205. [CrossRef]

Wall, David S. 2008. Cybercrime and the culture of fear: Social science fictions(s) and the production of knowledge about cybercrime. Information, Communication E Society 11: 861-84. [CrossRef]

Widom, Cathy Spatz, Sally J. Czaja, and Mary Ann Dutton. 2008. Childhood victimization and lifetime revictimization. Child Abuse E Neglect 32: 785-96. [CrossRef]

Wright, Michelle F., Bridgette D. Harper, and Sebastian Wachs. 2019. Differences in adolescents' response decision and evaluation for face-to-face and cyber victimization. Journal of Early Adolescence 39: 1110-28. [CrossRef] 